\title{
SMOKE FREE AREA (SFA) DISTRICT REGULATION SUPPORT FOR ESTABLISHMENT OF A CHILD FRIENDLY SCHOOL (CFS) IN KULON PROGO DISTRICT
}

\author{
Agri Aryoko $^{1}$, Oktavian Denta ${ }^{1}$, Iud Karnaningrum ${ }^{1}$, Arvicha Fauziah ${ }^{1}$, Theodola Baning ${ }^{1}$ \\ Synergy Together Reducing Cigarette Smoke in Kulon Progo (Semarku) \\ Kulon Progo District Health Office, Indonesia \\ Correspondence Address : Agri Aryoko \\ Email : Ktr.kulonprogo@gmail.com
}

\begin{abstract}
Following the Child-Friendly School (CFS) Guidelines made by the Deputy for Child Development, Ministry of Women Empowerment and Child Protection (2015), one of the components that must be fulfilled is a commitment to make schools a Smoke-Free Area (SFA). Kulon Progo has District Regulation No. 5 of 2014 concerning SFA, thus it can be used as a commitment by a school guide, making it an SFA. The results of interviews with the District Social Service for Women's Empowerment and Child Protection Office stated that CFS currently remains at the initiation stage. Efforts should be made to create comfortable learning conditions for children with the support of the SFA District Regulation in the formation of CFS in Kulon Progo Regency. Analysis of the implementation monitoring checklist/compliance with District Regulation No. 5/2014 concerning SFA in 2020 which is carried out by the SFA supervision task force. Descriptive analysis method by looking at trends based on the proportion of the 10 variables used. The results of the data study show that $89.5 \%$ have been exposed to the socialization of District Regulations, $52.6 \%$ have a supervisory task force, $86.8 \%$ have installed SFA signs at the Entrance, $100 \%$ have a smoking ban warning installed, $23.7 \%$ has a place specifically for smoking, $10.5 \%$ found an ashtray in the building, $7.9 \%$ found cigarette butts, $2.6 \%$ found cigarette advertisements, $5.3 \%$ found cigarette sellers, $7.9 \%$ smoked people. From the data analysis, it is known that $81.58 \%$ have complied with SFA. However, this compliance is not optimal. This is indicated by the high percentage of availability of designated smoking areas in schools and ashtrays, cigarette butts, cigarette advertisements, cigarette sellers, and smoking people found. Schools should have a zero percentage in these variables; thus, they are not fully committed as a condition for the formation of CFS. It is necessary to optimize the application of District Regulations to create a smoke-free school environment as evidenced by not providing smoking places in schools, not allowing cigarette advertisements, smoking outside, and imposing sanctions for non-smoking violators in the school environment.
\end{abstract}

Keywords: Support, Smoke-Free Area (SFA), Child Friendly Schools, Kulon Progo

\section{INTRODUCTION}

Air has a crucial function for human life and other creatures. In protecting air quality, efforts are needed to control sources of air pollutants and activities that potentially pollute the air, one of which is smoking. Cigarettes are rolls of tobacco (approximately the size of a little finger) wrapped in (palm leaves, paper) (Team, 2008).

The Indonesia Global Youth Tobacco Survey (GYTS) shows that the prevalence of smokers aged 13-15 years is $20.3 \%$. Moreover, $60.7 \%$ saw cigarette advertisement promotions from stores, $62.7 \%$ on TV and videos/movies, $7.9 \%$ had been offered cigarettes by salesmen. On the other hand, $70.1 \%$ saw the "quit smoking" message from the media, and $71.3 \%$ saw the pictorial health warnings (Indonesia, 2015). Cigarette consumption in Indonesia is believed to have a very broad negative impact, including health and the economy. Although smoking is the right of everyone, this also implies respect for the rights of 
others to have healthy and clean air. Therefore, it is imperative to implement steps for the Smoke-Free Area.

A smoke-free area is a place or room that is declared prohibited from smoking, producing, selling, advertising, and/or promoting cigarettes. The aim of implementing smoking-free areas is to reduce the number of morbidity and mortality due to smoking, while in general, its implementation helps to create a clean, healthy, safe and comfortable environment; protect non-smokers; reduce smoking rates, and prevent novice smokers (Team, 2010).

Child-Friendly School is a formal, non-formal, and informal education unit that is safe, clean, and healthy, cares and has an environmental culture, can guarantee, fulfill, respect children's rights and protection from violence, discrimination, and another mistreatment, and support children's participation, especially in planning, policies, learning, monitoring and complaint mechanisms related to the fulfillment of children's rights and protection in education (team, 2015).

The concept of a child-friendly school is an effort to realize the fulfillment of children's rights and protection for 8 hours of children in school, through these efforts to make schools: Clean, Safe, Friendly, Beautiful, Inclusive, Healthy, Beautiful, and Comfortable (Team, 2017).

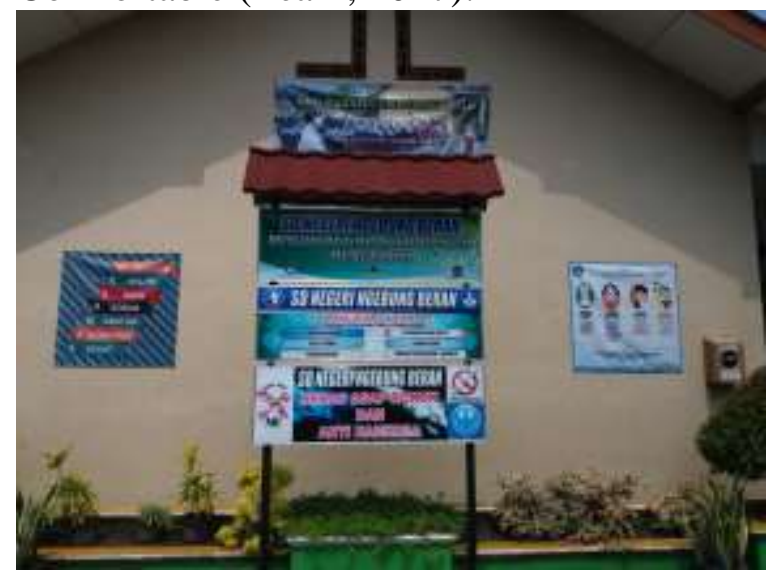

Figure 1. Children-friendly prep school signboard.
Child-Friendly Schools are also inseparable from the program to develop a Child-Friendly District because there are two fulfillments of 31 children's rights in a ChildFriendly District, one of which is through a Child-Friendly School existence. ChildFriendly Schools are a crucial indicator of the evaluation of Child-Friendly Districts. In addition, the purpose of formulating the Child-Friendly School Policy is to be able to fulfill, guarantee and protect children's rights, as well as ensure that education units can develop children's interests, talents, and abilities and prepare children to be responsible for a life of tolerance, mutual respect, and collaboration for progress spirit of peace. Hopefully, the education unit will not only produce an intellectually intelligent generation but also produce an emotionally and spiritually intelligent generation (Team, 2015).

One indicator of the Child-Friendly School policy is committing to create a smoke-free area in the school environment. This policy refers to 6 crucial components in implementing child-friendly schools, one of which is establishing child-friendly facilities and infrastructure. This shows that schools protect children's rights to grow and develop.

Following up on the impact of smoking on human health and the environment as well as protecting the younger generation from the dangers of cigarette smoke, the Kulon Progo Regency Government-issued District Regulation Number 05 of 2014 concerning Smoke-Free Area. Where one of the targets of this policy is teaching and learning places such as schools (Team, 2014).

The policies issued by the Kulon Progo district government are implemented in seven Smoke-Free Areas, one of which is a place for learning and teaching, namely a school. This implementation contains ten variables: 1) There has been socialization of District Regulation Number 5 of 2014 
concerning Smoke-Free Areas, 2) There is a Decree of the Supervision Task Force at the Institution / Target, 3) An announcement or sign of a Smoke-Free Area (at the Entrance) is attached, 4) A warning about smoking prohibition is attached (in the building), 5) there is no there is a designated smoking area (outside the building), 6) there is no ashtray in the building, 7) cigarette butts are not found in the Smoke-Free Area, 8) there are no cigarette advertisements in the SmokeFree Area, 9) there are no cigarette sellers in the area No smoking, 10) no one smokes. The policy of implementing a Smoke-Free Area must also be supported by public compliance and concern, thus government policies regarding smoke-free areas will later be able to save the fate of passive smokers, especially children, from being exposed to cigarette smoke in children's play areas and educational facilities (Team, 2015).

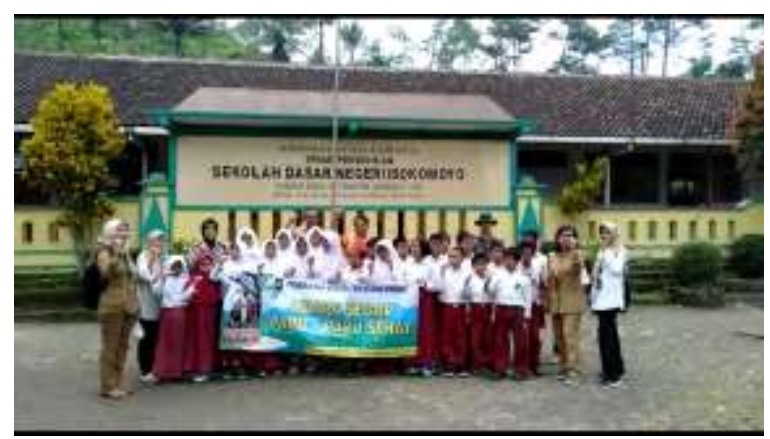

Figure 2. Declaration of Smoking Area Schools

According to the Gender and Child Information System (SIGA) belonging to the Ministry of Women's Empowerment and Child Protection, Kulon Progo Regency has three schools declared as Child Friendly Schools. This figure shows the smallest figure in the Special Region of Yogyakarta Province. According to Listiyani, the Head of the Section for Improving the Quality of Life of Children from the Social Service, Women's Empowerment and Child Protection, said that the Child Friendly
School in Kulon Progo Regency is still in the initiation stage and is still waiting for the governor's decree from the province. Twenty-nine schools have participated in the convention training on children's rights in preparation for the initiation of Child Friendly Schools (Team, 2020).

However, according to Eko Suratman, the Head of the Elementary School Student and Character-Building Section, the Education and Sports Office of Kulon Progo Regency, said that the implementation of school policies for the Smoke-Free Area Commitment is the responsibility of the school principal. According to him, all schools in Kulon Progo district have agreed to use the District Regulations for SmokeFree Areas number 5 of 2014 and its derivatives as a reference for committing to Smoke-Free Areas in schools.

This study will discuss how the District Regulations for Smoke-Free Areas support the establishment of child-friendly schools in Kulon Progo district through a tenvariable approach to implementing regulations in schools to create comfortable learning conditions for children with the support of District Regulations for SmokeFree Areas in the establishment of ChildFriendly Schools in the District Kulon Progo.

\section{METHOD}

Analysis of the monitoring checklist for the implementation / compliance of the District Regulations on Smoke Free Areas in 2020 were conducted by the task force for monitoring the Smoke Free Areas. The population used was elementary schools in Kulon Progo district with a sample of 38 primary schools listed in the monitoring list. Descriptive analysis method was by looking at trends based on the proportion of the 10 variables used. Ethical Number 1764/KEPUNISA/III/2021. 


\section{RESULT}

Table 1. Survey results using Checklist of Monitoring Implementation / Compliance of District Regulations for Smoke Free Area

\begin{tabular}{clcc}
\hline No & \multicolumn{1}{c}{ Variables } & n & $\%$ \\
\hline 1 & $\begin{array}{l}\text { There has been a socialization of District Regulations No. 5 of 2014 concerning } \\
\text { Smoke Free Areas }\end{array}$ & 34 & 89,5 \\
\hline 2 & There was a Decree of the Supervision Task Force at the Institution / Target & 20 & 52,6 \\
\hline 3 & Installed an announcement or sign for a Smoke Free Area (at the Entrance) & 33 & 86,8 \\
\hline 4 & Installed a no smoking warning (in the building) & 38 & 100 \\
\hline 5 & There was a designated smoking area (outside the building) & 9 & 23,7 \\
\hline 6 & There was an ashtray in the building & 4 & 10,5 \\
\hline 7 & Found cigarette butts & 3 & 7,9 \\
\hline 8 & Cigarette advertisements were found & 1 & 2,6 \\
\hline 9 & Found a cigarette seller & 2 & 5,3 \\
\hline 10 & There were people who smoke & 3 & 7,9 \\
\hline
\end{tabular}

Based on the survey results, it was found that from the total population sample, there were 34 schools with socialization of District Regulation Number 5 of 2014 concerning Smoke Free Areas with a percentage of $89.5 \%$. There were 20 schools with a percentage of $52.6 \%$, Announcement or sign of a Smoke Free Area (at the entrance) installed, a number of 33 schools with a percentage of $86.8 \%$, A no-smoking warning (in buildings) installed a number of 38 schools with a percentage of $100 \%$, there were designated smoking areas (outside the building) a number of 9 schools with a percentage of $23.7 \%$, there were ashtrays in the buildings of 4 schools with a percentage of $10.5 \%$, there were found cigarette butts of 3 schools with a percentage of $7.9 \%$, and there were cigarette advertisements for a number of 1 school with a percentage of $2.6 \%$. It was found that there were cigarette

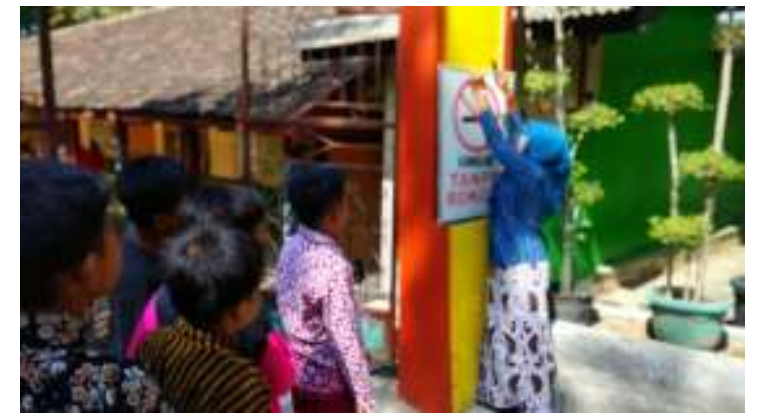

Figure 3. Installation of Smoke Free Area Signboard at School Entrance

sellers in 2 schools with a percentage of $5.3 \%$ and 3 schools with a percentage of people smoking with a percentage of $7.9 \%$.

\section{DISCUSSION}

According the results of the study, the fulfillment of the indicators for implementing local regulations in the school environment is 
as follows: Indicator 1: There has been a socialization of District Regulation No. 5 of 2014 concerning Smoke Free Areas. This indicator describes the education and outreach carried out by components of local authorities or other organizations regarding regional regulations on Smoke Free Areas. Socialization is an activity to socialize something thus it becomes known, understood, lived by the community (Bahasa, 2008). Hence, the socialization of Smoke Free Areas is intended to recognize, understand, and comply with regulations regarding Smoke Free Areas. This is in accordance with the Guidelines for the Development of a Smoking Free Area. Information dissemination and socialization of Smoking-Free Zones was undertaken by various methods and disseminated through the media on various occasions, thus the application of Smoking-Free Zones can be discovered and implemented by all parties, both high-ranking officials, supervisors and smokers and non-smokers. The imposition of sanctions is applied in accordance with the applicable laws and regulations (Team, 2010). It is known that $89.5 \%$ of the total sample have been exposed to education and socialization. This indicator indicates that most of the school samples already know that the Smoke Free Areas District Regulation is the main basis and the first step in implementing the Smoke Free Areas commitment in schools to strengthen Child Friendly Schools.

Indicator 2: There is a Decree of the Task Force for Supervision of Non-Smoking Areas in schools. This indicator illustrates the existence of implementation supervision performed by the supervisory task force in the school area. This indicator is an implementation of District Regulation no. 5 of 2014 article 18 paragraph 3 which stated "in order to carry out the supervisory obligation the leader / person in charge of the area may form a supervisory task force". It is known that $52.6 \%$ of the total sample have a Decree of the Task Force for Supervision of Smoke Free Areas to support the supervision of the Implementation of Regional Regulations on Smoke Free Areas. According to Lecturer at the Faculty of Law, Padjajaran University Abi Ma'ruf R. said that a decree signified the legal or juridical basis of all activities performed by officials and employees (Maulana, 2016). Thus, the Supervision Task Force Decree is very important to become the legal basis for the duties and authority of the Non-Smoking Area task force in schools. This indicates that the school is ready to oversee the implementation of the Smoke Free Area commitment. However, based on the survey, it was found that there were still $47.4 \%$ of schools that did not have a Decree on the task force for monitoring the Smoke Free Areas. By de facto, schools without decree were remains unknown whether they have implemented it or not. However, this needs attention because it can be said that there are schools that are still not ready to oversee the implementation of the No-smoking Zone commitment.

Indicator 3: There is a warning sign of Smoke Free Area at the Entrance. This indicator shows the availability of supporting facilities in the form of a Smoke Free Area signboard at the school entrance. This indicator is an implementation of the Regent Regulation No. 3 of 2015 article 13a which stated "to ensure that the leaders / person in charge of the school has posted a smoke-free area sign on the front page and / or a nosmoking sign at the main entrance and / or places deemed necessary and easy to read". It is known that $76.3 \%$ of the total sample has a warning sign of Smoke Free Area at the entrance. This indicates that most of the school samples have implemented the Smoke Free Area regulations by placing a warning sign of Smoke Free Areas at the Entrance. This is supported by the regulation of the 
minister of education and culture No. 64 of 2015 concerning smoking-free areas in school environments with the aim of article 2 to create a clean, healthy, and smoke-free school environment which is implemented in article $4 \mathrm{e}$ which stated "put up a smoke-free area sign. in the School Environment ". It is known that there are still $23.7 \%$ of the total sample who have not put up a sign announcing the Smoke Free Area at the entrance. This Smoke Free Area Notice Board is important because it informs visitors to the area that they are entering a smoke-free area.

Indicator 4: There is a warning sign that smoking is not allowed in the room. This indicator shows the availability of supporting facilities in the form of a warning sign that smoking is prohibited in the school room. This indicator is an implementation of District Regulation no. 5 of 2014 article 18 paragraph 2a which stated "in carrying out the obligation of supervision, the leader / person in charge of the area is authorized to put up signs" no smoking ". It is known that all samples have no smoking warning signs in the room. This indicates that all sample schools have a warning sign that smoking is prohibited in the room."

Indicator 5: There is a designated smoking area outside the building. This indicator shows the ownership of a designated smoking area outside the school building. This indicator is an implementation of the Regent Regulation No. 3 of 2015 article $13 \mathrm{c}$ which stated "prohibiting smoking places" in the school area. However, it is known that $76.3 \%$ of the total sample do not provide designated smoking areas. This indicates that the majority of the sample schools do not have designated smoking areas outside the building. Meanwhile, there were $23.7 \%$ of the sample still have designated smoking areas in schools. From the results of an interview with one of the persons in charge of Smoke Free Areas in the sample schools that still have designated smoking areas, they are usually located in the canteen and parking lot. Most of those who use the designated smoking area are parents who are waiting for their children, traders, and teachers. According to the District Regulation of Smoke Free Areas, special smoking areas outside buildings are only allowed in public places such as malls, markets, sports venues, and other public places as well as workplaces such as factories, offices, and other workplaces, not in schools or study areas. In the SRA policy, this is in accordance with the goals and principles of Child Friendly Schools, namely respecting the right to life, development, and survival of children. If there is a smoking area outside the room that is visible to children, this can be a means for children to be smokers in the future (Team, 2017)

Indicator 6: There is an ashtray in the building. This indicator illustrates the availability of smoking facilities in the room. This indicator is the implementation of regional regulations article 18 paragraph $2 \mathrm{~b}$ and Perbup No. 3 of 2015 article 13 e which reads "prohibiting ashtrays" in the school area. It is known that $89.5 \%$ of the total samples found no ashtrays in the building. while $10.5 \%$ of the total sample still found ashtrays in the building.

This indicates that most of the school samples do not have ashtrays in the building. The presence of an ashtray in the building indicates that smoking facilities are still provided in the building. Teaching and learning areas or schools are smoke-free areas that are not allowed to provide smoking facilities in order to suppress smoking behavior in the area. (Team, 2010) If the school still provides ashtrays, the school has not yet implemented the Child Friendly School concept for a healthy and comfortable school (Team, 2017). Schools also have not been able to create child-friendly facilities and infrastructure because they endanger 
children's health by allowing smokers to smoke in the room.

Indicator 7: cigarette butts are found. This indicator shows the presence of smokers in the school environment as evidenced by the discovery of cigarette butts in the school environment. This indicator is an implementation of District Regulationno. $5 / 2014$ concerning the definition of a smoking free area where smoking is prohibited in the area. It is known that $92.1 \%$ of the total sample did not find cigarette butts. While $7.9 \%$ of the total sample still found cigarette butts in the area. This indicates that the majority of the school samples were not found with cigarette butts. This indicator is still related to indicator No. 5 where there are still smoking areas that are used for pick-up parents, teachers, and food vendors in the school environment.

Indicator 8: cigarette advertisements are found. This indicator shows the existence of cigarette promotion and advertising efforts in the school environment. This indicator is an implementation of the Regent Regulation No. 3 of 2015 article 13 of which reads "prohibits people from carrying out activities in the form of selling, advertising or promoting cigarettes". It is known that $97.4 \%$ of the total sample did not find cigarette advertisements. This indicates that most school samples are not found in cigarette advertisements. Meanwhile, in $2.6 \%$ of the total sample, cigarette advertisements were still found. This is intended to refuse offers of advertising, promotion, sponsorship, and/or cooperation in any form made by cigarette companies and/or organizations that use trademarks, logos, slogans, and/or colors that can be associated with characteristics typical of cigarette companies, for curricular or extracurricular activities carried out inside and outside the school (Team, 2015). Many factors encourage and influence teenagers to smoke, one of which is advertising. Advertising is a medium to convey information to the public about a product and advertisements have a function to convey information, persuade, or remind people of cigarette products (Firmansyah, 2010)

Advertising, promotion, or sponsorship is an activity carried out by cigarette manufacturers to make it easier for cigarette producers to influence adolescents and children. Advertising greatly affects the lives of adolescents. Sometimes children who are novice smokers are due to seeing cigarette advertisements in their environment; children do not understand the dangers caused by smoking or the diseases that can arise due to smoking. This is following the goals of Child Friendly Schools which prevent children from becoming smokers and fulfill the safe concept of Child Friendly Schools (team, 2015).

Indicator 9: There are cigarette sellers found. This indicator shows the existence of a cigarette buying and selling business in the school environment. This indicator is an implementation of the Regent Regulation No. 3 of 2015 article $13 \mathrm{f}$ which reads "prohibits people from carrying out activities in the form of selling, advertising or promoting cigarettes". It is known that $94.7 \%$ of the total sample were not found to be cigarette sellers, while $5.3 \%$ of the total sample were still found to be cigarette sellers. This indicates that the majority of school samples found no cigarette sellers. This is also supported by the regulation of the minister of education and culture No. 64 of 2015 article $4 d$ which reads "prohibiting the sale of cigarettes in school canteens/stalls, cooperatives or other forms of the sale in the school environment".

Indicator 10: There are people smoking. This indicator illustrates that smokers are still found in the school environment. This indicator is an implementation of District Regulation no. $5 / 2014$ concerning the definition of a smoking free area where smoking is prohibited in the area. It is known that $92.1 \%$ 
of the total sample were not found to be smokers, this indicates that most of the school samples did not smoke. Meanwhile, $7.9 \%$ of the total sample still found people who smoked, some of them was a parent who waiting for their child at school in the parking lot. In schools where smoking is still found, the concept of being healthy and comfortable in Child Friendly Schools has not been fulfilled because schools still endanger children's health and do not adopt positive habits. The habit that is meant is the smoking habit of the parents which can be seen by the child as a negative habit (Empowerment, 2011).

\section{CONCLUSION}

Based on the survey results, the sample schools have used the basic 10 variables for implementing Smoke Free Areas according to Regional Regulations. However, these uses are not yet perfect. Real steps are needed to maximize the implementation by fulfilling ten variables of the District Regulation on Smoke Free Areas to create a smoke-free school environment and create a safe and comfortable environment.

The sample schools that have implemented the 10 variables are declared fully committed to smoking-free areas so that the school has met one of the criteria for child-friendly schools and is ready to become child-friendly schools. In its implementation, it is necessary to monitor the implementation of Smoking Free Areas in schools by related agencies so that schools are truly ready to become Child Friendly Schools.

\section{REFERENCES}

Empowerment, L. T. O. T. M. O. W. A. C., 2011. Regulation Of The Minister Of Women's Empowerment And Child Protection Of The Republic Of Indonesia Number 12 Of 2011
Concerning Child Friendly District Indicators. Jakarta: Ministry Of Women And Children Empowerment.

Firmansyah, A. A., 2010. The Relationship Between Parental Support, Peers And Cigarette Advertising With Smoking Behavior In Male Students Of Madrasah Aliyah Negeri 2 Boyolali. Universitas Muhammadiyah Surakarta.

Indonesia, M. O. H. R. O., 2015. Global Youth Tobacco Survey (Gyts) Indonesia Report, 2014. Jakarta: World Health Organisation.

Maulana, A., 2016. Decision Letters Are Not Just Administrative Documents. Bandung: Universitas Padjajaran.

Team, C. F. S., 2017. Child Friendly School Guide In School. Jakarta: Ministry Of Education And Culture.

Team, C. Q. O. L. I., 2020. School Attendance List For The Convention On The Rights Of The Child. Kulon Progo: Office Of Social Affairs, Women And Children Empowerment.

Team, D., 2015. Child Friendly School Guide. Jakarta: Ministry Of Women's Empowerment And Child Protection.

Team, L. C. D. C., 2008. Indonesian Dictionary. Xvi Ed. Jakarta: Language Center.

Team, L. G. L., 2014. Regional Regulation Of Kulon Progo Regency Number 5 Year 2014 Concerning No-Smoking Area. Kulon Progo: Local Government Of Kulon Progo Regency.

Team, L. G. L., 2015. Regulation Of The Regency Of Kulon Progo Number 3 Of 2015 Concerning Instructions For Implementation Of Regional Regulations Of Kulon Progo Regency Number 5 Of 2014 Concerning No Smoking Area. Kulon Progo: Local 


\section{Government Of Kulon Progo \\ Regency.}

Team, M. O. E. A. C. L., 2015. Regulation Of

The Minister Of Education And

Culture Of The Republic Of

Indonesia Number 64 Year 2015

Concerning No Smoking Area In The

School Environment. Jakarta:

Ministry Of Education And Culture.

Team, M. O. E. A. C. L., 2015. Regulation Of The Minister Of Education And Culture Of The Republic Of Indonesia Number 64 Year 2015 Concerning No Smoking Area In The School Environment. Jakarta: Ministry Of Education And Culture.

Team, M. O. H. P., 2010. Guidelines For The Development Of Non-Smoking Areas. Jakarta: Ministry Of Health. 